\title{
ZEBRA CROSSING
}

\section{Dear Reader,}

One might think that you or I would be able cross the road safely on a zebra crossing. But very often, these white stripes often fool us into a false sense of security - even though they have now been around for 60 years and have become a familiar sight on our roads. But one in every four zebra crossings is the scene of an accident, and at one in ten crossings the accidents even involve injuries to two or more people. These are figures taken from a six-year study carried out by the UDV (German Insurers Accident Research), which examined 400 zebra crossings in Germany.

The Federal Statistical Office in Wiesbaden arrives at similar numbers for 2011. There were 5362 accidents on zebra crossings, 31 of them with pedestrian fatalities. In $59 \%$ of the cases, the pedestrian was not at fault. A striking aspect is that above all under-15-year-olds and over60 -year-olds were particularly often the victims of accidents. Two years previously, according to the UDV, the accident statistics were similar, with 5506 persons involved, including 26 fatalities.

All of these figures are too high. In its "Stop, look, cross safely" campaign, the Auto Club Europa (ACE) is currently studying the reasons for these accidents. On the basis of the initial results already available, the ACE has specified the following requirements for safe crossings: unobstructed visibility (using bollards), clear road markings and signs, a crossing interrupted by a central island, lowered kerbstones and good lighting.

But we not only need to improve the road design itself. We also need to change our behaviour as road users. The ACE found that, out of 433 drivers, 57 failed to stop. 32 out of 180 pedestrians failed to look left and right before crossing. It comes as no surprise that cyclists are no better. Only 19 out of 71 cyclists stop at a zebra crossing, and only 14 out of 66 dismount and push their bicycle.

A new idea is now being proposed to improve safety on pedestrian crossings: a driver assistance system. The zebra crossing recognition system presented by Continental and Tokyo University on page 56 already has a high level of reliability, with correct recognition higher than $90 \%$ within a range of $20 \mathrm{~m}$. As soon as cameras and algorithms identify a zebra crossing and the movement of a pedestrian, a warning signal is given to the driver. I was impressed by the system during initial test drives. But, instead of giving a warning, wouldn't it be better to initiate obligatory braking?

Only by combining these three aspects road design, behaviour and driver assistance - will we move a step closer to “Vision Zero". You will certainly find out more at the stands of OEMs and suppliers at the IAA in Frankfurt. I look forward to discussing the topic with you at our ATZ stand at the show. You can find us from 10 to 13 September in Hall 4.1. Stand 24. I hope to see you there.

Best regards,

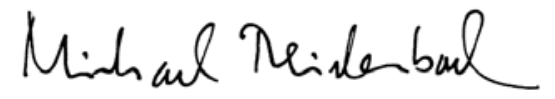

DIPL.-ING. MICHAEL REICHENBACH,

Vice-Editor in Chief

Wiesbaden, 16 July 2013

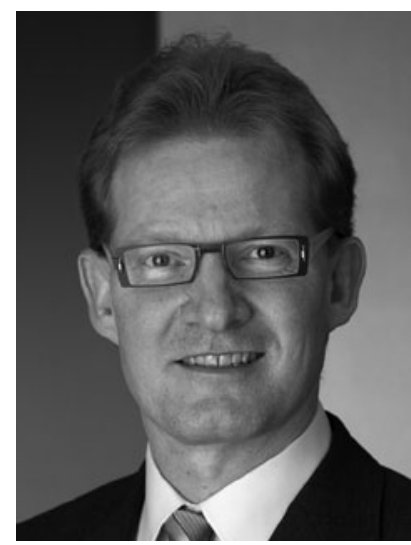

